Stefan Zweig como mediador cultural em Brasil, um país do futuro: aplicação prática no ensino de alemão e/ou português como língua estrangeira | 193

\title{
STEFAN ZWEIG COMO MEDIADOR CULTURAL EM BRASIL, UM PAIS DO FUTURO: APLICAÇÃO PRÁTICA NO ENSINO DE ALEMÃO E/OU PORTUGUÊS COMO LÍNGUA ESTRANGEIRA
}

Tito Lívio Cruz Romão ${ }^{1}$

Resumo: Filho de um rico empresário têxtil judeu, Stefan Zweig nasce na Áustria. Quando os nazistas tomam o poder na Alemanha em 1933 e promovem queimas de livros, obras suas também são alvos dessas ações. Em 1941, emigra com sua segunda esposa, Lotte, para o Brasil, indo viver em Petrópolis. O ditador Getúlio Vargas concede-lhe visto de permanência, por Zweig, supostamente, "cheio de entusiasmo por um país onde não parecia haver vestígios de conflito racial e agradecido por ter encontrado abrigo" (Die Zeit, 2013/07/02), ter escrito o livro Brasil, um país do futuro. Sofrendo de depressão, Zweig, juntamente com Lotte, suicida-se em 1942, ingerindo barbitúricos. Com base em conceitos factuais de cultura e civilização (faktische Landeskunde; cf. Biechele/Padrós, 2003, 21ff.), neste artigo examinaremos fatos descritos e números apresentados na obra supramencionada quanto a aspectos geográficos, históricos, sociais e culturais. Mediante uma abordagem contrastiva, cotejaremos fatos e números daquela época, por amostragem aleatória, com as condicionantes ora vigentes, para constatarmos se/como o país louvado por Zweig mudou, após quase oito décadas. Analisaremos, por fim, se a imagem do Brasil apresentada por Zweig coincide, na visão dos leitores atuais, com a realidade brasileira hodierna, e, se essa imagem necessitar de "atualização", como alguns trechos da obra poderiam ser alterados, visando-se à tematização de aspectos interculturais (p. ex. com uma abordagem centrada na ação e nos aprendizes; cf. Bischof/Kessling/Krechel 2003, 33ff.) no ensino de alemão e/ou português como língua estrangeira.

Palavras-chave: Stefan Zweig - Cultura e civilização brasileira - Tentativas de atualização.

Zusammenfassung: Als Sohn eines wohlhabenden jüdischen Textilunternehmers wird Stefan Zweig in Österreich geboren. Als die Nationalsozialisten 1933 die Macht in Deutschland ergreifen und

${ }^{1}$ Prof. Adjunto UFC - cruzromao@terra.com.br 
Bücherverbrennungen veranstalten, landen auch seine Bücher auf dem Scheiterhaufen. 1941 emigriert er mit seiner zweiten Frau Lotte nach Petrópolis/Brasilien. Daueraufenthalt bekommt Zweig von Diktator Getúlio Vargas, weil er „aus Begeisterung über ein Land, in dem von Rassenkonflikten nichts zu spüren war, und aus Dankbarkeit, Schutz gefunden zu haben“ (Die Zeit, 7.2.2013), das Buch „Brasilien, ein Land der Zukunft" geschrieben habe. Unter Depressionen leidend, tötet sich Zweig 1942 gemeinsam mit Lotte durch Schlafmitteleinnahme. Basierend auf dem Modell der faktischen Landeskunde (vgl. z.B. Biechele/Padrós 2003, 21ff.) sollen in dem o.g. Werk Zweigs über Brasilien beschriebene Fakten bzw. präsentierte Zahlen in geographischer, historischer, gesellschaftlicher und kultureller Hinsicht untersucht werden. Nach einem kontrastiven Vorgehen werden damalige Fakten und Zahlen mit z.Zt. bestehenden Verhältnissen stichprobeweise konfrontiert, um herauszufinden, ob/wie sich nach knapp acht Jahrzehnten das von Zweig besungene Land verändert hat. Der vorliegende Beitrag geht also der Frage nach, ob sich das von Zweig überlieferte Brasilienbild bei heutigen Lesern mit der gegenwärtigen Realität Brasiliens deckt, und - falls dieses Bild „aktualisierungsbedürftig“ sein sollte - wie manche Stellen von seinem Buch für Unterrichtszwecke (z.B. nach einem handlungs- bzw. lernendenorientierten Ansatz; vgl. Bischof/Kessling/Krechel 2003, 33ff.) umgewandelt werden könnten.

Schlüsselwörter: Stefan Zweig - Landeskunde Brasiliens Aktualisierungsversuche.

Ninguém que já esteve aqui gosta de dar adeus. Em cada despedida e em cada lugar acende-se o desejo de voltar. Beleza é algo raro, e beleza perfeita, quase um sonho. A cidade mais bela de todas as cidades torna esse sonho realidade, mesmo nas horas sombrias; não existe outra cidade no mundo que saiba nos consolar. ${ }^{2}$ Stefan Zweig, 2008, p. 193

2 Trecho original: „Niemand nimmt gern Abschied, der hier einmal gewesen. Bei jedem Fortreisen und von jedem Ort wünscht man sich zurück. Schönheit ist selten und vollendete beinahe ein Traum. Diese eine Stadt unter den Städten macht ihn wahr auch in düstersten Stunden; es gibt keine tröstlichere auf Erden." (ZWEIG, 1997, p. 219) 
Stefan Zweig como mediador cultural em Brasil, um país do futuro: aplicação prática no ensino de alemão e/ou português como língua estrangeira | 195 Introdução

Aos 28 de novembro de 1881, nascia na cidade de Viena, então capital do Império Austro-Húngaro, Stefan Samuel Zweig, filho de um empresário judeu do ramo têxtil e de uma senhora austríaca oriunda de uma rica família de comerciantes. Em seus cursos superiores, dedicou-se à Filosofia e às Letras Germânicas e Neolatinas, tendo estudado nas universidades de Viena e de Berlim. Após seu doutoramento, empreendeu uma série de viagens por diversos países. Muito cedo, ainda nos anos do liceu vienense, descobriu seu pendor pela literatura, deixando-se inspirar por autores de expressão alemã como Hugo von Hofmannsthal e Rainer Maria Rilke. Precocemente, ainda no início do século XX, já começou a traduzir autores franceses e em 1910 publicou sua primeira obra biográfica, um livro dedicado à vida do poeta belga Émile Verhaeren. Cedo também se tornou amigo do escritor francês Romain Rolland, com quem passou a compartilhar firmes ideias pacifistas durante os anos da Primeira Guerra Mundial. Nas décadas seguintes, sua produção literária ganhou grande projeção em dimensão e prestígio, mas seu sucesso junto ao público viria a esbarrar na ascensão do austríaco Adolf Hitler ao poder na vizinha Alemanha.

Segundo o crítico literário Marcel Reich-Ranicki ${ }^{3}$, Stefan Zweig "foi um escritor invulgarmente prolífico, fértil e multifacetado. Escreveu dramas, poesia, novelas, romances, lendas, ensaios, reportagens, memórias, diários. Além disso, traduziu Baudelaire, Verlaine, Verhaeren, dentre outros literatos" ${ }^{4}$. Em meio ao grande número de obras literárias

${ }^{3}$ Nascido na Polônia em 1920, no seio de uma família teuto-polonesa de confissão judaica, M. Reich-Ranicki foi obrigado a viver no Gueto de Varsóvia, onde atuou como tradutor os serviços administrativos do regime hitlerista. Participou da resistência contra o nazismo e logrou fugir de Varsóvia em 1943, antes da dissolução do Gueto. Após ter servido no Exército e no Serviço Diplomático polonês, em 1958 mudou-se para a Alemanha Ocidental. Pouco tempo depois, já dominava a cena da crítica literária na Alemanha, onde figurou como uma celebridade durante décadas. Morreu em 2013 aos 93 anos.

4 Texto originalmente publicado em alemão no Frankfurter Allgemeine Sonntagszeitung, em 25/10/2008, no 43, p. 31: O texto em português encontra-se publicado no portal da Casa Stefan Zweig, sem nenhuma indicação do nome da pessoa que o traduziu, podendo ser visualizado 
que Zweig publicou, merecem destaque, à guisa de exemplo, os perfis biográficos - ensaísticos ou romanceados - de personagens mundialmente conhecidos, tais como Maria Antonieta, Honoré de Balzac, Charles Dickens, Dostoievski, Joseph Fouché, Américo Vespúcio, Erasmo de Roterdã, Fernão de Magalhães, Romain Rolland, Maria Stuart e Michel de Montaigne. Em 1942, houve uma publicação póstuma de sua autobiografia Die Welt von gestern: Erinnerungen eines Europäers ${ }^{5}$, em que apresenta uma visão sociopolítica dos tempos que vivera entre sua juventude na capital austríaca até sua morte em Petrópolis.

Em 1934, Zweig refugiou-se em Londres. Em 1936, quando esteve pela primeira vez no Brasil para proferir palestras ${ }^{6}$ sobre sua produção literária, seus livros já faziam parte das obras proibidas de serem comercializadas na Alemanha de Hitler e, portanto, passíveis de serem queimadas. Com a anexação da Áustria pelo regime nacional-socialista alemão em 1938, sua vida na Áustria tornara-se impraticável, obrigando Zweig a optar por solicitar a nacionalidade britânica, que the foi concedida em 1940. Nesse mesmo ano, a partir de Londres, tornou a empreender viagens às Américas, quando mais uma vez visitou o Brasil. Aos 5 de novembro de 1940, o Ministério das Relações Exteriores do Brasil concedeu, a ele e à sua segunda esposa, Lotte, visto de permanência.

No Brasil, Zweig certamente ficou conhecido - e sempre será lembrado - pela publicação de sua obra Brasilien - Ein Land der Zukunft, título que foi traduzido em português ora por Brasil - um país do futuro, ora por Brasil - o país do futuro ${ }^{7}$. Nesse livro, publicado em 1941 no Brasil

\footnotetext{
através

do

seguinte

link:

http://www.casastefanzweig.org/sec texto view.php?id=59.

(Último acesso: 18/06/2017).

${ }^{5}$ No Brasil, essa obra foi traduzida por Kristina Michahelles e recebeu o seguinte título: Autobiografia: o mundo de ontem. Memórias de um europeu (ZWEIG, 2014).

${ }^{6} \mathrm{Na}$ verdade, fez uma breve pausa no Rio de Janeiro, antes de se dirigir a Buenos Aires, onde participaria de uma reunião do PEN Clube.

${ }^{7}$ A respeito desse tema, escreve Dines (2012, p. 426): "Identificado o autor da façanha de encontrar a entonação épica para uma das obras que, sem ela, seria apenas curiosa, resta saber quem surrupiou o artigo indeterminado do título Brasilien, ein Land der Zukunft. Sem o artigo, a expressão ganhou determinação, passou a ser afirmativa, caso das versões
} 
Stefan Zweig como mediador cultural em Brasil, um país do futuro: aplicação prática no ensino de alemão e/ou português como língua estrangeira | 197 e em Portugal, o autor austríaco-judeu apresenta um panorama detalhado do Brasil a partir das impressões que já começara a colher em suas primeiras viagens por diferentes regiões brasileiras. Na primeira viagem, em 1936, esteve no Brasil apenas de passagem; ele mesmo registrou que ficar uns dez dias lhe parecia "o suficiente para quem não era nem geógrafo profissional nem colecionador de borboletas, caçador, desportista ou comerciante". Na segunda viagem, em 1941, havia se divorciado de sua primeira esposa, Friederike, e já se encontrava casado com Lotte. Essa sua segunda visita ao Brasil fazia parte de uma turnê que incluía Rio de Janeiro e São Paulo, além de Montevidéu, Buenos Aires e outras cidades argentinas. Foi em Buenos Aires que soube, no consulado brasileiro, que seu visto de residência permanente fora concedido. Em seguida, visitou algumas cidades das regiões Norte e Nordeste do Brasil, quando aproveitou para aprofundar suas impressões sobre a diversidade cultural e os recursos naturais e econômicos do país. Naquela altura, seu editor no Brasil, Abraham Koogan, já fora avisado de sua intenção de escrever uma obra sobre o Brasil ${ }^{8}$.

Em agosto de 1941, Zweig e Lotte chegam ao Brasil. "Desgostoso com as críticas ao livro e os rumores de que o teria escrito para agradar ao

inglesa (Brazil, Land of the Future), português (Brasil, país do futuro), espanhola (Brasil, pais del futuro) e mesmo francesa (Le Brésil, terre de l'avenir). 'Brasil, um país do futuro' admite outros países nas mesmas condições. Na edição brasileira, a supressão do artigo pode ter sido um agrado de Koogan ao governo Vargas, ou obediência à sintética opção inglesa. Funcionou. Não foi dele uma das mais felizes criações numa excepcional coleção de títulos.” Observe-se, ainda, que o título de uma edição mais moderna do livro publicada na Espanha (cf. ZWEIG, 2006) prescinde de todo e qualquer artigo: Brasil. Pais de futuro. Quanto às primeiras edições em língua inglesa, a tradução feita por Andrew St. James e publicada nos Estados Unidos (ZWEIG, 1941) e em países da Comunidade Britânica (ZWEIG, s.d.) não utiliza o artigo: Brazil, Land of the Future. Contudo, em uma tradução mais moderna, publicada nos Estados (ZWEIG, 2000), adota-se o artigo indefinido: Brazil, a Land of the Future. 8

http://www.casastefanzweig.org/sec cronologia.php?language=pt br\&pa ge=2. (Último acesso: 07/08/2017). 
governo" , o casal resolveu não ficar na cidade do Rio, preferindo instalarse em um bangalô na cidade fluminense de Petrópolis. Ali Zweig escreveria a novela Schachnovelle (Xadrez, na tradução de Pedro Süssekind) e também seu último ensaio biográfico, dedicado ao filósofo Michel de Montaigne. À semelhança do humanista renascentista francês, Zweig tentava buscar paz e compreensão entre as pessoas, cultuando a tolerância e a autocontemplação. Mas a depressão e a tristeza diante das monstruosidades da guerra, combinadas à saudade de sua terra, foram mais fortes, e entre a noite de 22 e a manhã de 23 de fevereiro de 1942, Zweig e sua esposa cometeram o suicídio.

Alberto Dines (2012, p. 460) ressalta a "ancestral imagem da terra do porvir" descrita na Carta de Pêro Vaz de Caminha ${ }^{10}$, mas, ao prefaciar o livro Brasil, um pais do futuro (ZWEIG, 2008), parece esquecer-se, embora apenas por alguns breves momentos, da importância do escrivãomor da frota de Pedro Álvares Cabral, cuja missiva a El-Rei Dom Manuel é reputada inclusive como a certidão de nascimento do Brasil:

É o mais famoso de todos os textos que se escreveram sobre o Brasil. De 1500 até 1941 (quando saiu a primeira edição) e mesmo agora, 65 anos depois, nenhuma obra foi tão traduzida, tão reeditada e tão citada quanto esta ode de Stefan Zweig ao país que o abrigou durante a Segunda Guerra Mundial. E onde se matou, junto com a mulher Lotte, oito meses depois. (ZWEIG, 2008, p. 7)

http://www.casastefanzweig.org/sec_cronologia.php?language=pt_br\&pa ge $=2$. (Último acesso: 07/08/2017.)

${ }^{10}$ A título de exemplo, Caminha (2000, p. 180) salienta a qualidade da terra achada pela frota de Cabral: "Esta terra, Senhor, me parece que da ponta que mais contra o sul vimos até outra ponta que contra o norte vem, de que nós deste porto houvemos vista, será tamanha que haverá nela bem vinte ou vinte e cinco léguas por costa. Traz ao longo do mar em algumas partes grandes barreiras altas, delas vermelhas, delas brancas e a terra por cima toda chã e muito cheia de grandes arvoredos. De ponta a ponta é toda praia palma muito chã e muito formosa. (...) Águas são muitas, infindas. Em tal maneira é graciosa que, querendo-as aproveitar, dar-se-á nela tudo, por bem das águas que tem." 
Stefan Zweig como mediador cultural em Brasil, um país do futuro: aplicação prática no ensino de alemão e/ou português como língua estrangeira | 199

A gênese e a motivação dessa obra não aconteceram livres de polêmicas junto à imprensa e aos pensadores brasileiros. Geraram-se, no Brasil, alguns debates, ainda inconclusos, especulando-se, por exemplo, se a escrita do livro teria tido como escopo uma forma de agradecimento endereçado ao então ditador Getúlio Vargas, à frente do Estado Novo, que de início acenara simpaticamente para Hitler e Mussolini. Por outro lado, como relata Dines (2012, p. 14), "o livro foi recebido no exterior como revelação, [mas] aqui com incompreensão, os patriotas de plantão não suportaram a ideia de um gringo assenhoreando-se da mãe-pátria”. Por ocasião do $75^{\circ}$ aniversário de morte do casal Zweig, um duplo suicídio por ingestão de uma superdose do sedativo e sonífero Veronal, o escritor alemão Joachim Lottmann, em um artigo publicado em 22/02/2017 no caderno cultural do jornal alemão Die Welt teceu os seguintes comentários:

Mas agora vamos direto ao ponto: os intelectuais brasileiros recusaram Brasil, um pais do futuro. Afirmavam tratar-se de uma encomenda para o governo brasileiro, que, havia alguns anos, se encontrava no caminho que conduziria à típica ditadura sul-americana.

Em 1936, quando Zweig esteve a primeira vez no Rio de Janeiro, pouco se podia ver a esse respeito. $O$ presidente Vargas parecia ser um homem que queria fazer algo pelos judeus deportados, e assim Zweig foi bem-intencionado em seu contato com ele. Posteriormente, relutava em achar que o ditador normal Vargas e o genocida racista Hitler fossem farinha do mesmo saco. Zweig não era tão simples quanto os esquerdistas locais (e hoje também não seria). De imediato, ele foi tolhido, evitado, até mesmo desprezado e caluniado de antissemitismo nos círculos frequentados pelos críticos do Rio de Janeiro. Isso, e apenas isso, rouboulhe a vontade de socializar-se por lá. ${ }^{11}$ (minha tradução)

\footnotetext{
${ }^{11}$ No original: "Doch nun zum Punkt: die brasilianischen Intellektuellen lehnten „Brasilien, ein Land der Zukunft“ ab. Sie behaupteten, es sei eine Auftragsarbeit für die brasilianische Regierung gewesen, die sich seit einigen Jahren auf dem Weg in die übliche südamerikanische Diktatur befand. Im Jahre 1936, als Zweig erstmals in Rio landete, war davon noch wenig zu sehen gewesen. Präsident Vargas schien ein Mann zu sein, der
} 
Entre os críticos brasileiros que repreendiam Zweig encontravamse, por exemplo, alguns jornalistas, dentre os quais Pedro da Costa Rego, redator-chefe do Correio da Manhã, que "insinua maliciosamente a riqueza e o comercialismo do escritor" (DINES, 2012, 446). O mesmo jornal sempre ficará a postos na tentativa de encontrar flancos abertos para atacar o autor. Mas Zweig também encontrará opositores nas pessoas de Ribeiro Couto, que, à serviço da ditadura de Vargas, estava preocupado com o tipo de migrantes que o Brasil deveria acolher (id., p. 473). Jorge Amado, Carlos Drummond de Andrade, Rubem Braga e Joel Silveira, como bem destaca Dines (id., p. 475), também emitiriam opiniões duvidosas sobre o escritor-refugiado, de certo modo comprovando a difícil situação de calúnia a que Zweig se viu sujeito após a publicação de seu livro.

Se a voz corrente sustenta a tese do suicídio de Zweig e Lotte, há também quem tenha um outro entendimento sobre o que realmente ocorreu naquela noite fatídica e até mesmo antes dela. Em uma publicação do Suplemento Literário de Minas Gerais (SLMG), mais precisamente na edição de número 58 , de abril de 2000, alguns juristas encabeçados por Jacob Pinheiro Goldberg expõem uma tese contrária, ressaltando a possibilidade de ter sido um assassinato. No dia 16 de julho de 1998, Diana Canneti (DC), jornalista alemã da Rádio Düsseldorf entrevistou Goldberg (JPG). Veja-se, a seguir, uma pequena parte do diálogo:

DC: Em primeiro lugar, eu gostaria que o Sr. fizesse uma apresentação de sua pessoa.

etwas für die vertriebenen Juden tun wollte, und so begegnete Zweig ihm wohlwollend. Später dann widerstrebte es ihm, den normalen Diktator Vargas in einen Topf mit dem rassistischen Massenmörder Hitler zu werfen. So simpel wie die landesüblichen Linken war Zweig nicht (und wäre es auch heute nicht). Prompt wurde er geschnitten, gemieden, ja verachtet und auch antisemitisch verleumdet in den Kritikerkreisen Rio de Janeiros. Das und nur das hat ihm die Lust auf Geselligkeit dort genommen."

https://www.welt.de/kultur/literarischewelt/article162270682/Derwahre-Grund-fuer-den-Selbstmord-von-Stefan-Zweig.html; último acesso em 07/08/2017.) 
Stefan Zweig como mediador cultural em Brasil, um país do futuro: aplicação prática no ensino de alemão e/ou português como língua estrangeira | 201 JPG: Eu sou psicanalista e advogado. Esta formação intelectual me levou à suspeita relacionada com a versão oficial da morte de Stefan Zweig. Essa versão nunca me convenceu. Eu nasci no interior de Minas Gerais, em Juiz de Fora, em 1933. Meus pais eram judeus poloneses imigrantes. Uma vez, meu pai conversando com o rabino Tzekinowski, lhe disse: "A Gestapo é capaz de fazer qualquer coisa”, isso em relação ao crime cometido contra Stefan Zweig. $\mathrm{Na}$ minha opinião, houve uma lavagem cerebral e ciladas circunstanciais que conduziram de alguma maneira à morte dele e de sua esposa. Eu não tenho a menor dúvida de que a Gestapo, com a colaboração da polícia política de Getúlio Vargas, ensejou, provocou a morte de Stefan Zweig e de sua mulher. (SLMG, 2000)

Goldberg também sustenta que a carta de despedida escrita por Zweig teria sido forjada pela polícia política, pois esse documento, escrito originalmente em alemão, encimado com o título Declaração ${ }^{12} \mathrm{em}$ português, pouca ou nenhuma relação teria com o estilo e a estética do escritor. Léopold Stern, conhecido dos Zweig que mais tarde escreveria um opúsculo intitulado A morte de Stefan Zweig (STERN, 1942), recebera na manhã do dia 23/02/1942 um telefonema de Cláudio de Souza,

12 Eis o texto da Declaração, conforme Stern (1942, p. 17s.): “Antes de deixar a vida, por minha própria vontade, e na posse de meus sentidos, sinto-me impelido a cumprir um último dever: agradecer profundamente a este admirável país, o Brasil, que me proporcionou, a mim e ao meu trabalho, uma tão amável hospitalidade. Cada dia aprendi a amar mais este país e em nenhuma outra parte teria querido reconstruir radicalmente minha vida, depois que o mundo de minha própria língua soçobrou para mim e que minha pátria espiritual, a Europa, se destrói a si própria. Mas, depois dos sessenta anos, forças novas seriam necessárias para recomeçar inteiramente. E as minhas, após meus longos anos de peregrinação sem pátria, estão esgotadas. Julgo, portanto, que mais vale concluir em tempo, e de pé, uma existência na qual o trabalho espiritual sempre foi a maior alegria, e a liberdade pessoal o mais elevado dos bens desta terra. Saúdo a todos os meus amigos! Que lhes seja dado ver ainda a aurora, após a longa noite. Eu, por demais impaciente, parto antes. Stefan Zweig. Petrópolis, 22-II-1942.” 
presente do P.E.N. Club e amigo íntimo de Zweig. De automóvel, os dois rapidamente se dirigiram à residência do casal, acompanhados de Alfred Agache, urbanista francês, que primeiro soubera da triste notícia e prevenira Cláudio de Souza. Stern descreve a cena com estas palavras:

Instintivamente, dirigimos nossos olhos para o mesmo lugar: a porta de entrada [da casa], diante da qual dois policiais, uniformizados, montam guarda. Paralisados, nenhum de nós se atreve a tentar adivinhar o que se terá passado. Chegando ao topo da tortuosa escada que leva à residência, passamos diante de uma janela que sabemos ser o quarto de dormir. Um de nós, involuntariamente, lança um olhar, exclamando: horrível! É minha vez de olhar. Lá, sobre o leito, Stefan Zweig está estendido ao lado de sua mulher. Estão estreitamente abraçados, ela a cabeça contra o peito do marido. (STERN, 1942, p. 10s.)

Nesta altura, lembramos que o presente artigo não tem por objetivo discutir, de modo conclusivo, se a morte dos Zweig foi decorrente de assassinato ou suicídio. Não obstante, os dados apresentados acima são importantes, para se destacarem diversos aspectos que denotam a relevância do escritor para as belas letras em escala internacional. E que também mostram seu importante papel, de modo particular, para o Brasil, já que Zweig ajudou, sobremaneira, apesar das ferrenhas críticas desferidas contra ele, a tornar a terra e a gente brasileira mais conhecidas no exterior. Logo em sua estreia, o livro Brasil, um país do futuro teve traduções para o português, inglês, francês, espanhol e sueco.

A seguir, faremos uma breve discussão sobre a questão da Landeskunde (aspectos de cultura e civilização) no ensino de alemão como língua estrangeira (ALE). Em seguida, apresentaremos alguns temas de cultura brasileira extraídos do livro Brasil, um país do futuro, a fim de verificarmos se os dados ali contidos ainda são válidos em nossos dias ou se necessitariam ser atualizados, caso o livro venha a ser utilizado, por exemplo, no ensino de ALE. Essas discussões deverão ensejar a elaboração de materiais que poderão ser utilizados no ensino de ALE para aprendizes brasileiros, mas também de português como língua estrangeira (PLE) para aprendizes estrangeiros em geral. Acreditamos em estratégias de ensino voltadas para o aprendiz de língua estrangeira (LE) e centradas em ações a serem realizadas. Isto significa que em primeiro plano não deverá 
Stefan Zweig como mediador cultural em Brasil, um país do futuro: aplicação prática no ensino de alemão e/ou português como língua estrangeira | 203 despontar "o debate sobre os textos, mas aquilo que se pode fazer com os textos" (BISCHOF/KESSLING/KRECHEL 2003, 162 ${ }^{13}$ ) Esse tipo de abordagem se mostra ideal para o trabalho com textos literários que precisem, à guisa de exemplo, ser reescritos, alterados, atualizados etc., ou em que os alunos sejam instigados a assumir o papel de personagens de algum texto estudado em situações de ensino de ALE/PLE.

\section{Landeskunde como componente de ensino de ALE}

No ensino de ALE, é comum se utilizar o termo Landeskunde, que, traduzido no contexto brasileiro, pode ser entendido de forma genérica como "aspectos de cultura e civilização". Partiremos aqui de uma situação de ensino de ALE, embora entendamos que o material compilado e apresentado por Zweig em seu livro possa ser usado em diferentes situações de aula. A versão brasileira da obra, por exemplo, poderia ser empregada em aulas de PLE. E a edição alemã, por sua vez, também poderia ser utilizada com alunos falantes de alemão como língua materna que precisassem discutir questões relacionadas ao Brasil.

Seja como for, é importante traçarmos aqui um breve perfil do termo Landeskunde e de suas ramificações. Já podemos adiantar que as discussões sobre esse tema, que foram iniciadas nos anos 1970 e aprofundadas ao longo dos anos 1980, 1990, 2000 e 2010, ainda não foram definitivamente concluídas. Os debates também provocaram “reorganizações" estratégicas nas áreas de Linguística e de Teoria Literária. No início dos anos 1990, o romanista alemão Robert Picht, ao dissertar sobre os diferentes lobbies que se haviam formado em torno desse tema, brindou seus leitores com um breve resumo sobre as mudanças em curso ou já concluídas àquela época:

Para além do debate sobre Landeskunde, falsificado através de interesses grupais e de mal-entendidos muitas vezes intencionais, debate esse que também foi realizado em

13 Segundo a visão desses mesmos autores (id., p. 33), esse tipo de abordagem é importante quando o aluno está às voltas com atividades destas naturezas: a) remodelar um texto; b) concluir um texto previamente iniciado; c) assumir a perspectiva de um personagem e refletir o que ele próprio faria na pele do outro; d) escrever um diário; e) escrever uma carta; f) escrever e representar um diálogo. 
outros países como conflito entre tradição e modernidade, a Linguística e a Teoria Literária igualmente passaram a entrar em movimento. A Pragmática passou a refletir sobre estes aspectos: os atos de fala extraem seu sentido de situações concretas da comunicação social, e também é preciso, paralelamente às distinções existentes entre as línguas, que se levem em consideração as diferenças culturais extralinguísticas. A Semântica voltou a ser trabalhada com mais intensidade, passando a fazer referência às relações reais, ou seja, sempre também às relações sociais culturalmente específicas dos campos conceituais por ela investigados. A Teoria Literária, por sua vez, pôs-se a pesquisar as condições sociais da produção e da recepção literária, desenvolvendo, assim, elementos de uma sociologia literária que também se refiram às especificidades das culturas nacionais. (PICHT, 1991, p. 55; minha tradução) $)^{14}$

Anos mais tarde, com o estabelecimento e a consolidação dos fenômenos registrados por Picht (1991), já se podia falar claramente de diferentes tipos de Landeskunde. Ulrich Zeuner (2001/2009), em um trabalho sobre aprendizagem intercultural, compilando ideias de diferentes autores, ressalta a existência de três tipos de abordagem para a

${ }^{14}$ Trecho no original alemão: „Jenseits dieser durch Gruppeninteressen und oft gewollte Missverständnisse verfälschten ,Landeskundediskussion“, die als Konflikt zwischen Tradition und Moderne ähnlich auch in anderen Ländern ausgetragen wurde, gerieten auch Linguistik und Literaturwissenschaft in Bewegung. Pragmalinguistik besann sich darauf, dass Sprechakte ihren Sinn aus konkreten Situationen gesellschaftlicher Kommunikation beziehen, dass neben der Unterschiedlichkeit der Sprachen auch außersprachliche kulturelle Differenzen zu berücksichtigen sind. Semantik wurde wieder intensiver betrieben und verwies auf die realen, das heißt immer auch kulturspezifisch gesellschaftlichen Bezüge der von ihr untersuchten Begriffsfelder. Literaturwissenschaft erforschte die gesellschaftlichen Bedingungen literarischer Produktion und Rezeption und entwickelte damit Elemente einer Literatursoziologie, die sich ebenfalls auf die Spezifika der nationalen Kulturen beziehen." 
Stefan Zweig como mediador cultural em Brasil, um país do futuro: aplicação prática no ensino de alemão e/ou português como língua estrangeira | 205 Landeskunde: abordagem cognitiva, abordagem comunicativa e abordagem intercultural.

$\mathrm{Na}$ abordagem cognitiva, afirma Zeuner (2001/2009, p. 11), os conteúdos de aprendizagem são preponderantemente relacionados a conhecimentos factuais e ao domínio de diferentes temas, tais como: tipos de moradias na Alemanha; tipos de paisagens, instituições (p. ex.: o Bundestag ou Parlamento Alemão, o sistema eleitoral alemão etc.); aspectos históricos (o Tratado de Potsdam, a guinada ocorrida na antiga República Democrática Alemã etc.); aspectos culturais (museus em Dresden, Goethe em Weimar etc.) etc. Como muito bem mostram os exemplos elencados, trata-se, neste caso, da chamada "faktische Landeskunde" (aspectos factuais de cultura e civilização), como também apontam Biechele e Padrós (2003) mediante a seguinte definição:

[Trata-se de] Um modelo de Landeskunde, que tem por base a transmissão de informações factuais: o conhecimento temático sobre um país ocupa o primeiro plano. Tematizam-se fatos geográficos, históricos, culturais; números e datas têm grande importância. Designam-na também como Landeskunde explícita. (BIECHELE; PADRÓS, 2003, p. 145; minha tradução) ${ }^{15}$

Em segundo lugar, Zeuner (2001/2009, p. 10s.) apresenta a abordagem comunicativa. Segundo o autor, é importante destacar a virada que o ensino de línguas estrangeiras experimentou a partir dos anos 1970, quando se começou a trilhar a chamada metodologia comunicativa do ensino de línguas estrangeiras, em que os "conteúdos de aprendizagem não eram mais vinculados a 'objetos' e/ou a instituições da cultura estrangeira", dando-se lugar, agora, a "experiências, conhecimentos e posicionamentos dos aprendizes” (ibid.). É preciso ater-se à "cultura cotidiana" e aos processos normais do dia-a-dia (refeições, moradia, relacionamentos interpessoais), entendendo-se que é necessário comunicar-se com a alteridade, com o estrangeiro. No processo de

${ }^{15}$ Cf. o trecho original em alemão: „Ein Landeskundenmodell, das auf Tatsachenvermittlung beruht: Das sachliche Wissen über ein Land steht im Vordergrund. Thematisiert werden geographische, historische, kulturelle Fakten; Zahlen und Daten spielen eine wichtige Rolle. Man spricht auch von expliziter Landeskunde." 
aprendizagem, os professores deixam de ser o foco principal de atenção, cedendo esse posto aos aprendizes.

A terceira abordagem de Landeskunde apresentada por Zeuner (2001/2009) é a intercultural. Segundo o autor, os aspectos linguísticos de um sistema estrangeiro, por si sós, ainda que utilizados corretamente, não bastariam para se gerar comunicação. A partir dos anos 1980, já também se fazia mister a "dependência mútua entre aprendizagem linguística e cultural”, ou seja, defendia-se ser necessário entender melhor “a própria cultura e a cultura estrangeira" (ZEUNER, 2001/2009, p. 11). Agora já não bastavam apenas conhecimentos cognitivos, pois, no ensino de línguas estrangeiras, é preciso, sobretudo, trazer à baila "o desenvolvimento de capacidades, estratégias e habilidades no contato com culturas e sociedades estrangeiras" (ibid.).

A partir das noções de Landeskunde explanadas acima à luz das três abordagens propostas por Zeuner (2001/2009), apresentaremos a seguir alguns exemplos extraídos do livro Brasil, um país do futuro. Nosso objetivo será mostrar se, mediante uma proposta de atualização de alguns trechos escritos por Zweig, seria possível utilizar esse tipo de discussão como estratégia de ensino de língua estrangeira. Utilizaremos, no corpo deste artigo, os exemplos em língua portuguesa, por entendermos, como já afirmamos mais acima, que essa estratégia de ensino poderia ser usada tanto em aulas de ALE quanto de PLE.

\section{O Brasil de Zweig e o Brasil atual}

Qualquer pessoa com conhecimento sobre dados geográficos, econômicos, demográficos, dentre outros, sobre o Brasil atual ficará, ao se deparar com alguns trechos do livro em questão, espantado com algumas das informações ali contidas. Aspectos culturais, ligados, por exemplo, a questões étnicas e sociais, também serão fontes fáceis para discussões sobre as grandes mudanças por que o Brasil tem passado nos últimos 80 anos.

Se nos ativermos aos dados do Instituto Brasileiro de Geografia e Estatística (IBGE), verificaremos que o Brasil descrito por Zweig tinha uma população de cerca de 42 milhões de habitantes ${ }^{16}$. Em agosto de

16 Cf. os dados em: http://brasil500anos.ibge.gov.br/estatisticas-dopovoamento/evolucao-da-populacao-brasileira.html. (Último acesso: 07/08/2017). 
Stefan Zweig como mediador cultural em Brasil, um país do futuro: aplicação prática no ensino de alemão e/ou português como língua estrangeira | 207 2016, o IBGE publicou, no Diário Oficial da União, a estimativa da população brasileira, indicando que o Brasil já contava com 206.081 .432 habitantes ${ }^{17}$. Se voltarmos ao ano de 1934, veremos que a cidade de São Paulo então contava com 1.060.120 habitantes; em 1940, era um total de 1.337.644 paulistanos, a uma taxa de crescimento anual em torno de 4\% (ZANIRATO, 2000). Sobre São Paulo, Zweig afirmava: "É difícil ter uma imagem estática de São Paulo porque a cidade está constantemente se ampliando, porque é demasiado irrequieta em sua rápida transformação” (ZWEIG, 2008, p. 194). Examinando os números relativos ao Rio de Janeiro, constatamos que no ano de 1940 a então capital do Brasil ostentava uma população de $1.764 .141^{18}$ habitantes. Para melhor entendermos esse contexto de explosão demográfica brasileira nos grandes centros urbanos, observem-se estes dados:

A população urbana brasileira teve uma grande expansão na segunda metade do século XX onde, segundo Santos (2008), entre 1940 e 1980 triplica a população total do Brasil, ao passo que a população urbana se multiplica por sete vezes e meia, podendo causar uma série de problemas sociais e ambientais devido ao crescimento não planejado das cidades. Esse crescimento urbano é ligado a uma rápida aceleração de setores econômicos industriais e de serviços que, demandando por mão de obra, acabam impulsionando o crescimento urbano dos municípios (OLIVEIRA et alii, 2015, 3503).

O crescimento demográfico explosivo das duas maiores metrópoles brasileiras fica evidente, quando consultamos a projeção atual de seu número de habitantes conforme dados do IBGE. A população atualmente projetada para a cidade de São Paulo é de 12.038 .175 , e a projetada para a cidade do Rio de Janeiro, de 6.498 .837 de habitantes. Esses dados são relativos à população residente nas duas cidades com data de referência

17 http://g1.globo.com/economia/noticia/2016/08/brasil-tem-mais-de206-milhoes-de-habitantes-segundo-o-ibge.html. (Último acesso: 07/08/2017).

18 http://www.skyscrapercity.com/showthread.php?t=638799. (Último acesso: 07/08/2017) 
em $1^{\circ}$ de julho de $2016^{19}$. É importante lembrar que na época em que Zweig escreveu o livro ainda faltavam cerca de 20 anos para a inauguração de Brasília, que atualmente já conta com 2.977.216 habitantes, sendo, segundo as estimativas do IBGE em 2016, a 3a cidade mais populosa do país, atrás apenas de São Paulo e do Rio de Janeiro.

Em 1940, o IBGE, criado no final dos anos 1930 com a fusão entre o Conselho Brasileiro de Geografia e o Instituto Nacional de Estatística, elaborou uma nova proposta de divisão regional do Brasil. Conforme essa nova ideia, deveriam ser levados em consideração os aspectos físicos e também os aspectos socioeconômicos. Na nova configuração, havia as seguintes regiões: a) Região Norte: Amazonas, Pará, Maranhão, Piauí e território do Acre; b) Região Centro: Goiás e Mato Grosso; c) Região Leste: Bahia, Sergipe e Espírito Santo; d) Região Nordeste: Ceará, Rio Grande do Norte, Pernambuco, Paraíba e Alagoas; e) Região Sul: Paraná, Santa Catarina, Rio Grande do Sul, São Paulo e Rio de Janeiro (v. Fig. 1).

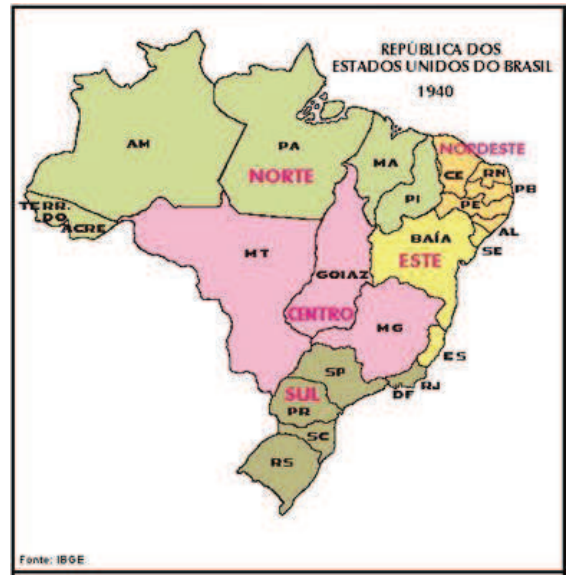

Fig. 1: Divisão regional do Brasil em $1940^{20}$

19

http://www.ibge.gov.br/home/estatistica/populacao/estimativa2016/esti mativa dou.shtm. (Último acesso: 07/08/2017.)

${ }^{20}$ Fonte:

http://www.geografia.seed.pr.gov.br/modules/galeria/detalhe.php?foto=1 557\&evento=5. (Último acesso: 07/08/2017) 
Stefan Zweig como mediador cultural em Brasil, um país do futuro: aplicação prática no ensino de alemão e/ou português como língua estrangeira | 209

Em um texto intitulado Breve histórico da configuração políticoadministrativa brasileira (disponível no portal do IBGE), Amanda Estela Guerra explica o desenvolvimento imediatamente posterior a 1940. Essa evolução provocaria uma reconfiguração do mapa brasileiro em relação às diferentes regiões, representando, portanto, um mapa diferente daquele que Zweig conhecera ao escrever seu livro:

Na década de 1940, no contexto da Segunda Guerra Mundial e com a necessidade crescente de exploração da borracha na Amazônia, o então presidente da República Getúlio Vargas criou cinco Territórios Federais, a partir do desmembramento dos Estados do Amazonas e Pará, sendo eles: Guaporé, Amapá, Ponta Porã, Iguaçu e Rio Branco. Desses, dois foram extintos em 1946: Ponta Porã e Iguaçu. A intervenção federal nos estados foi explicada pela necessidade da segurança das fronteiras, localizadas em regiões remotas onde o poder público estadual encontrava dificuldades em administrar. ${ }^{21}$

Devemos lembrar que essa intervenção federal foi baseada no texto da Constituição Brasileira de $1937^{22}$, que permitia que a União desmembrasse estados já existentes e, no intuito de fomentar e promover a defesa nacional, criasse novos Territórios Federais, como os descritos acima.

Atualmente, o Brasil é uma República Federativa composta de um único território, como assinala a Constituição Federal de $1988^{23}$, formado de 26 estados e do Distrito Federal (Brasília). Em sua atual divisão

21

http://www.ibge.gov.br/home/geociencias/geografia/default evolucao.sh tm. (Último acesso: 07/08/2017.)

22 “Art 6 - A União poderá criar, no interesse da defesa nacional, com partes desmembradas dos Estados, territórios federais, cuja administração será regulada em lei especial.”

23 Art. 1A República Federativa do Brasil, formada pela união indissolúvel dos Estados e Municípios e do Distrito Federal, constitui-se em Estado democrático de direito e tem como fundamentos: I - a soberania; II - a cidadania; III - a dignidade da pessoa humana; IV - os valores sociais do trabalho e da livre iniciativa; $\mathrm{V}$ - o pluralismo político. 
político-administrativa, o Brasil compõe-se de cinco grandes regiões, como se pode depreender a partir da Fig. 2.

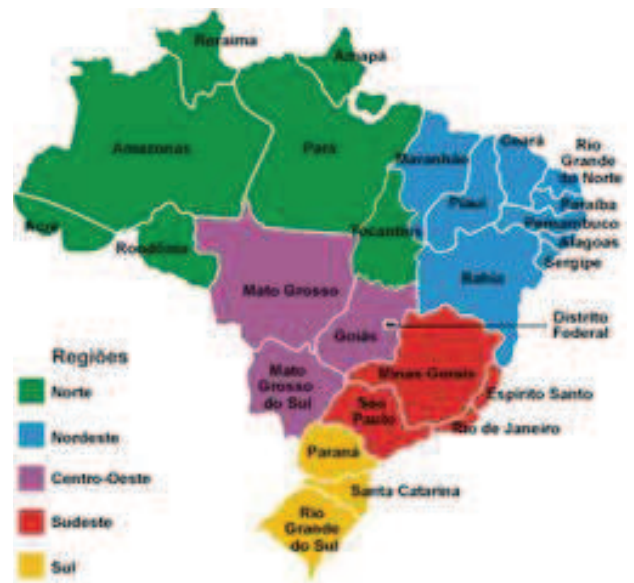

Fig. 2: Divisão político-administrativa do Brasil atual ${ }^{24}$

Um outro aspecto que merece ser destacado na tentativa de atualização de algumas informações contidas na obra Brasil, um país do futuro é, sem dúvidas, a temática da constituição étnica do povo brasileiro. Stefan Zweig, que vinha passando por sérios problemas, que muito o entristeciam, devido à grande e destruidora onda racista que assolava a Europa de Hitler e Mussolini, sentiu-se embevecido ao chegar ao Brasil. A partir de seu texto, entendemos que ele não aprofundara - nem ninguém o advertira disso - seus conhecimentos em relação às crueldades perpetradas por portugueses e brasileiros, entre outros povos, contra a população autóctone brasileira e contra milhões de africanos que foram sequestrados de suas terras em diferentes regiões da África e transformados em escravos no Brasil. Talvez o próprio escritor nos forneça, já no início de seu famoso livro sobre o Brasil, uma pista que aponta para essa sua falta de conhecimentos sobre o tema:

Em termos culturais, o Brasil é, até hoje, a mesma terra incógnita que, no sentido geográfico, foi para os primeiros navegantes. Volta e meia me surpreendo com os conceitos

24 Fonte: http://brasilescola.uol.com.br/brasil/divisao-regionalbrasileira.htm. (Último acesso: 07/08/2017) 
Stefan Zweig como mediador cultural em Brasil, um país do futuro: aplicação prática no ensino de alemão e/ou português como língua estrangeira | 211 confusos e insuficientes que mesmo pessoas eruditas e politicamente interessadas têm acerca desse país o qual, no entanto, indubitavelmente está fadado a ser um dos fatores mais importantes do desenvolvimento futuro do nosso mundo. (ZWEIG 2008, p. 14)

É óbvio que o Brasil, àquela época, ainda era um país amplamente desconhecido pelo mundo afora, embora saibamos das relações familiares estabelecidas entre a Coroa Portuguesa e a Casa de Habsburgo da Áustria, de onde provinha a Imperatriz Leopoldina ${ }^{25}$. Zweig parece não ter percebido o que havia por baixo da aparente "paz" entre as etnias constitutivas do Brasil, um país que, apenas meio século antes, abolira a escravidão, mas não conseguira (e ainda não conseguiu) eliminar o grande fosso que separa(va) afro-brasileiros do restante da sociedade. Entendemos que o escritor, muito abalado com a violência estabelecida na Alemanha de Hitler contra os judeus, ficara bastante impressionado e comovido ao ver a (relativa) "paz" em que viviam os brasileiros oriundos das mais diversas etnias. Veja-se este trecho de sua obra:

Pela sua estrutura etnológica, caso tivesse acompanhado a loucura nacionalista e racista da Europa, o Brasil deveria ser o país mais dividido, menos pacífico e mais conturbado do mundo. Nas ruas e nos mercados, é possível distinguir claramente as diferentes raças de que a população é composta. Há os descendentes dos portugueses, que conquistaram e colonizaram o país, a população indígena originária que habita o interior desde tempos imemoriais, os milhões de negros trazidos da África nos tempos da escravidão, e, depois, os milhões de italianos, alemães e japoneses que vieram como colonos. (ZWEIG, 2008, p. 18)

25 Carolina Josefa Leopoldina Francisca Ferdinanda de HabsburgoLorena, nascida arquiduquesa da Áustria, princesa da Hungria e da Boêmia, em 22.01.1797, filha do Imperador da Áustria, Francisco I, e de sua segunda esposa, a Princesa Maria Teresa Carolina de Nápoles e da Sicília. Foi a primeira esposa de Dom Pedro I e desempenhou papel importante no projeto de independência do Brasil. 
Vê-se, a partir da citação precedente, que Zweig destaca a "loucura nacionalista e racista" ("Nationalitäten- und Rassenwahn"; ZWEIG, 1997, p. 12s.) do regime nazista, contrapondo-a à harmonia de "raças" então existente, em seu modo de entender, no território brasileiro. Vale destacar que, devido ao emprego abusivo e mal-intencionado da palavra "Rasse" alemã pelos nazistas, atualmente se precisa estar atento ao utilizála. Segundo o Dicionário Duden, a palavra "Rasse" tem o seguinte significado: "Totalidade dos animais decorrentes de uma determinada cepa, mais raramente também [totalidade] das plantas de um gênero, que se distinguem dos outros do mesmo gênero através de determinados traços comuns." 26 No mesmo dicionário, encontra-se a seguinte advertência, que certamente ainda não era feita antes do holocausto programado e realizado por Hitler:

Observação importante: na Biologia o termo Rasse não é mais empregado para seres humanos. Quando se quiser fazer referência às respectivas diferenças, deve-se recorrer a formas alternativas, tais como Menschen anderer Hautfarbe (pessoas de outra cor de pele). ${ }^{27}$

Para deixar ainda mais evidente sua surpresa com a diversidade étnica e com a (aparente!) harmonia reinante entre os representantes dos diversos grupos que já compunham o cadinho étnico-cultural da população brasileira, Zweig prossegue:

Do ponto de vista europeu, seria de esperar que cada um desses grupos fosse hostil com os outros - os que chegaram

26 „Gesamtheit der auf eine Züchtung zurückgehenden Tiere, seltener auch Pflanzen einer Art, die sich durch bestimmte gemeinsame Merkmale von den übrigen derselben Art unterscheiden." (http://www.duden.de/rechtschreibung/Rasse; último acesso: 07/08/2017).

27 "Besonderer Hinweis: In der Biologie wird der Begriff der Rasse nicht mehr auf Menschen angewendet. Wenn auf entsprechende Unterschiede Bezug genommen werden muss, sollten deshalb Ausweichformen wie Menschen anderer Hautfarbe gewählt werden." (http://www.duden.de/rechtschreibung/Rasse; último acesso: 07/08/2017). 
Stefan Zweig como mediador cultural em Brasil, um país do futuro: aplicação prática no ensino de alemão e/ou português como língua estrangeira | 213 primeiro com os que vieram depois, brancos contra negros, americanos contra europeus, morenos contra amarelos; que as maiorias e as minorias se hostilizassem em uma disputa incessante pelos seus direitos e privilégios. Para surpresa, descobre-se que todas essas raças, que já pela cor evidentemente se distinguem umas das outras, convivem em plena harmonia e, apesar das diferentes origens, apenas competem no empenho de acabar com suas diversidades a fim de se tornarem rapidamente brasileiros, de constituir uma nação nova e homogênea.

No trecho acima, vemos o detalhamento das cores de pele, importante pormenor para Zweig naquela época prenhe de conflitos em torno da origem dos habitantes da Alemanha hitlerista. Destaque-se, para ilustrar, a designação "de cor parda”, que gera, por vezes, debates no Brasil, já que para alguns pode significar uma cor indefinida, como se vê na expressão "eminência parda" ("graue Emminenz", em alemão, e "eminência cinza", na retrotradução). Por outro lado, o termo "pardo" consta na lei no 12.288, de 20 de julho de 2010, que institui o Estatuto da Igualdade Racial. $^{28}$ A própria lei recebe críticas por reunir, sob a denominação "população negra”, pretos e pardos: "Existe diferença no comportamento social entre pretos e pardos: quanto mais escuro, mais discriminado" 29 , afirma, por exemplo, José Luiz Petruccelli, que realiza pesquisas sobre diversidade racial há mais de 20 anos no IBGE.

Semelhantemente ao termo "Rasse", um outro vocábulo usado por Zweig no original precisaria ser rediscutido à luz das mudanças ocorridas no uso do alemão das últimas décadas. Ao referir-se a negros/pretos, Zweig utiliza ora a palavra "Neger" ora a palavra "Schwarze(r)". O Dicionário Duden também faz uma advertência a seus usuários:

28 “[...] População negra: o conjunto de pessoas que se autodeclaram pretas e pardas, conforme o quesito cor ou raça usado pela Fundação Instituto Brasileiro de Geografia e Estatística (IBGE), ou que adotam autodefinição análoga; [...]”. Para maiores detalhes, cf.: http://www.planalto.gov.br/ccivil 03/ Ato20072010/2010/Lei/L12288.htm . (Último acesso: 07/08/2017)

29 https://www.pragmatismopolitico.com.br/2013/05/diferencas-entrenegro-pardo-e-preto.html. (Último acesso: 07/08/2017) 
No uso oficial, considera-se o termo Neger fortemente discriminatório, devendo, assim, ser evitado. Como termos alternativos, existem: Farbiger, Farbige [homem, mulher de cor] e Schwarzer, Schwarze [negro, negra/preto preta]; essa última designação pode ser encontrada amiúde em textos sobre a África do Sul, certamente para referir-se inequivocamente à população negra (p. ex. em oposição a indianos). Pessoas de pele escura que vivem na Alemanha costumam escolher a autodenominação Afrodeutscher, Afrodeutsche" [afro-alemã, afro-alemão], que cada vez mais ganha espaço. ${ }^{30}$

Pode-se imaginar que a própria hesitação, por parte de algumas pessoas, na hora da escolha entre "negro" ou "preto" no Brasil atual já pode apontar para uma escolha política. Além disso, o termo "de cor" também merece ser analisado com maior rigor, pois seu uso atual também é eivado de problemas. Na primeira versão de Brasil, um país do futuro em português, feita por Odilon Gallotti, o tradutor utiliza o termo "vermelho", para verter o vocábulo "Braune" usado por Zweig:

Ao passo que na Europa, agora mais do que nunca, domina a quimera de quererem criar seres humanos "puros", quanto à raça, como cavalos de corrida ou cães de exposição, a nação brasileira há séculos assenta no princípio da mescla livre e sem estorvo, da completa equiparação de preto, branco, vermelho e amarelo (ZWEIG, 1960 (1942), p. 8).

30 http://www.duden.de/rechtschreibung/Neger. Texto original: „Die Bezeichnung Neger gilt im öffentlichen Sprachgebrauch als stark diskriminierend und wird deshalb vermieden. Als alternative Bezeichnungen fungieren Farbiger, Farbige sowie Schwarzer, Schwarze; letztere Bezeichnung ist z.B. in Berichten über Südafrika vermehrt anzutreffen, wohl um eindeutiger auf die schwarze Bevölkerung (etwa im Unterschied zu Indern) Bezug nehmen zu können. In Deutschland lebende Menschen mit dunkler Hautfarbe wählen häufig die Eigenbezeichnung Afrodeutscher, Afrodeutsche, die zunehmend in Gebrauch kommt." (Último acesso: 07/08/2017.) 
Stefan Zweig como mediador cultural em Brasil, um país do futuro: aplicação prática no ensino de alemão e/ou português como língua estrangeira | 215

É preciso salientar que Gallotti realizou sua tradução antes que ocorressem no Brasil muitas discussões sobre a questão das populações indígena e afro-brasileira. Na tradução de Kristina Michahelles, vê-se sua clara opção pelo termo "morenos" em lugar de "vermelhos":

Enquanto, no nosso velho mundo, prevalece a loucura de se querer criar pessoas de "raça pura", como se fossem cavalos de corrida ou cães, a nação brasileira se baseia há séculos unicamente no princípio da mistura livre e sem entraves, a total equiparação entre negros e brancos, morenos e amarelos. ${ }^{31}$

Em outro trecho, Gallotti também utiliza o vocábulo "morenos" como tradução de "Mischling": "É raro que em qualquer outra parte do mundo se possam ver mulheres e crianças morenas mais bonitas do que essas criaturas gráceis e de maneiras tão suaves (...)” (ZWEIG, 1960 [1942], p. 9). Michahelles (ZWEIG, 2008, p. 19) traduz o termo "Mischling” por mestiço.

\section{Considerações finais}

Podemos concluir que o livro Brasil, um pais do futuro é uma fonte quase inesgotável de temas para discussões em cursos de ALE e/ou PLE, e notadamente para a elaboração de exercícios que tenham como fim uma atualização dos dados relativos à cultura e civilização brasileira registrados por Zweig.

Vimos, a partir de alguns exemplos escolhidos aleatoriamente, que alguns temas relacionados a aspectos geográficos, históricos, etnográficos, culturais, políticos, dentre muitos outros, podem facilmente ser explorados em exercícios que levem em conta a chamada Landeskunde em qualquer das abordagens propostas por Zeuner (2001/2009). Pode-se igualmente inferir que, para além de aulas de ALE e/ou PLE, o texto

31 "Während es in unserer alten Welt mehr als je der Irrwitz vorherrscht, Menschen "rassisch rein” aufzuzüchten zu wollen wie Rennpferde oder Hunde, beruht die brasilianische Nation seit Jahrhunderten einzig auf dem Prinzip der freien und ungehemmten Durchmischung, der völligen Gleichstellung von Schwarz und Weiß und Braun und Gelb." (ZWEIG, 1997 , p. 13) 
original de Zweig, em cotejo com as traduções existentes em português, também pode render trabalhos profícuos no âmbito de cursos de formação e/ou treinamento de tradutores e intérpretes.

E, por fim, se retomarmos a epígrafe deste artigo, em que Zweig louva a cidade do Rio de Janeiro, já teríamos bastantes temas a abordar e tratar apenas com base nas transformações sofridas pela antiga capital brasileira ao longo das últimas 8 décadas.

\section{REFERENCIAS BIBLIOGRAFICAS}

BIECHELE, Markus; PADRÓS, Alicia. Didaktik der Landeskunde. Berlim; Munique; Viena; Zurique; Nova Iorque: Goethe-Institut Inter Nationes, 2003.

BISCHOF, Monika; KESSLING, Viola; KRECHEL, Rüdiger. Landeskunde und Literaturdidaktik. Berlim; Munique; Viena; Zurique; Nova Iorque: Goethe-Institut Inter Nationes, 2003.

CAMINHA, Pêro Vaz de. A Carta de Pêro Vaz de Caminha. Mafra: Mar de Letras, 2000.

DINES, Alberto. Morte no paraíso. A tragédia de Stefan Zweig. Rio de Janeiro; Rocco, 2012.

FREYRE, Gilberto. Casa grande e senzala. Rio de janeiro/São Paulo: Record, 2000.

OLIVEIRA, Paula de; et alii. Dinâmica espacial da população do Rio de Janeiro entre 1970 e 2010 utilizando geotecnologias. In: Anais XVII Simpósio Brasileiro de Sensoriamento Remoto - SBSR, João Pessoa-PB: INPE

PICHT, Robert. Kultur- und Landeswissenschaften. In: Karl-Richard Bausch; Herbert Christ; Werner Hüllen; Hans-Jürgen Krumm (org.). Handbuch Fremdsprachenunterricht. Tübingen: Francke Verlag, 1991.

SCHÜLER, Heinrich. Brasilien. Ein Land der Zukunft. Stuttgart/Leipzig: Deutsche Verlags-Anstalt, 1912.

STERN, Léopold. A morte de Stefan Zweig. Rio de Janeiro: Editora Civilização Brasileira, 1942.

ZANIRATO, Sílvia Helena. São Paulo 1930/1940: novos atores urbanos e normatização social. In: Revista da Pós-Graduação em História IFCH UNICAMP n 7, 2000.

ZEUNER, Ulrich. Landeskunde und interkulturelles Lernen. Dresden: Institut für Germanistik, 2009 (2001). 
Stefan Zweig como mediador cultural em Brasil, um país do futuro: aplicação prática no ensino de alemão e/ou português como língua estrangeira | 217 ZWEIG, Stefan. Brazil, Land of the Future. Trad. Andrew St. James. Londres/Toronto/Melbourne/Sydney: Cassell and Company, Ltd., s.d.

ZWEIG, Stefan. Brasil - Pais do Futuro. Trad. Odilon Gallotti. Sintra: Colares Editora, s. d.

ZWEIG, Stefan. Brazil, Land of the Future. Trad. Andrew St. James. Nova Iorque: The Viking Press, 1941.

ZWEIG, Stefan. Le Brésil, terre d'avenir. Trad. Jean Longeville. Querigny: Éditions de l'Aube, 2005.

ZWEIG, Stefan. Brasil - ein Land der Zukunft. Frankfurt am Main / Leipzig: Insel Verlag, 1997.

ZWEIG, Stefan. Brasil, pais do futuro. Trad. Odilon Gallotti. Rio de Janeiro: Editora Delta, 1960 (1942).

ZWEIG, Stefan. Tagebücher. Frankfurt am Main: S. Fischer verlag, 1984.

ZWEIG, Stefan. Brazil, a land of the future. Trad. Lowell A. Bangerter. Riverside, California: Ariadne, 2000.

ZWEIG, Stefan. Brasil, pais de futuro. Trad. Alfredo Cahn. Barcelona: Ediciones Cahoba, 2006.

ZWEIG, Stefan. Medo, Amok e Xadrez. Trad. de Lia Luft e Pedro Süssekind. Porto Alegre, RS: Editora L\&PM, 2007.

ZWEIG, Stefan. Brasil, um pais do futuro. Porto Alegre, RS: Editora L\&PM, 2008.

ZWEIG, Stefan. Die Welt von gestern: Erinnerungen eines Europäers. Frankfurt am Main: S. Fischer, 1982

ZWEIG, Stefan. Autobiografia: o mundo de ontem. Trad. de Kristina Michahelles. Rio de Janeiro: Zahar, 2014.

Recebido em: 10 de agosto de 2017.

Aceito em: 10 de setembro de 2017. 